\title{
Proton Pump Inhibitors and Mucus Secretion
}

\author{
Mario Guslandi
}

Published online: 31 October 2009

(C) Springer Science+Business Media, LLC 2009

I have read with great interest the article by Sarosiek et al. [1] reporting a stimulatory effect of rabeprazole on esophageal mucin. The article describes a pharmacological property which may have a pivotal role in protecting the esophageal mucosa against gastro-esophageal reflux and which appears to be unique in comparison with other proton pump inhibitors (PPIs).

As quoted by Sarosiek et al., if we take into consideration the influence of PPIs on gastric mucin, neither omeprazole nor lansoprazole were found to increase gastric mucus secretion in experimental studies.

On the contrary, we already reported, in a double-blind placebo-controlled study, that, in humans, a 4-week treatment with omeprazole $20 \mathrm{mg}$ significantly reduces the amount of total and neutral mucoproteins into the gastric juice, as well as the viscous and protective properties of gastric mucus as assessed by means of a 'mucoprotective index' [2]. Gastric mucus secretion reverts to normal only 2 weeks after the drug withdrawal.

Similar results were observed with lansoprazole (Guslandi et al., unpublished data). Hence, the finding of a mucus-stimulating effect by rabeprazole suggests that this effect is unrelated to the inhibition of the gastric proton pump and may be due to its specific chemical structure.
Similar discrepancies have been shown in our past studies with other acid-inhibiting agents, H2-receptor antagonists. While cimetidine and famotidine promote qualitative alterations in gastric mucus secretion, other $\mathrm{H} 2$-blockers such as ranitidine and nizatidine have no similar effects [3, 4].

The ability of rabeprazole to enhance gastric and esophageal mucus secretion represents an additional therapeutic effect of remarkable value in clinical practice.

\section{References}

1. Sarosiek I, Olyaee M, Majewski M, , Sidorenko E, Roeser K, Sostarich S, Wallner G, Sarosiek J. Significant increase of esophageal mucin secretion in patients with reflux esophagitis after healing with rabeprazole: its esophagoprotective potential. Dig Dis Sci. 2009;54:2137-2142.

2. Guslandi M, Franceschi M, Fanti L, Pellegrini A, Tittobello A. Omeprazole-induced changes in gastric mucus secretion. Methods Find Exp Clin Pharmacol. 1992;14:219-223.

3. Guslandi M, Ballarin E, Tittobello A. Gastric mucus secretion in ranitidine-treated patients. Br Med J. 1981;283:699.

4. Guslandi M, Battaglia A, Pamparana F, Passaretti S, Pellegrini A, Tittobello A. Weakening effect of famotidine but not of nizatidine on the mucus-bicarbonate barrier of the human stomach. Drugs Exp Clin Res. 1990;16:481-485.
M. Guslandi $(\bowtie)$

Gastroenterology Unit, S. Raffaele University Hospital,

Milan, Italy

e-mail: guslandi.mario@hsr.it 